\title{
Gestational Sleep Apnea
}

\author{
Mohamed Nabih EL Gharib* \\ Professor of Obstetrics \& Gynecology, Tanta University, Egypt
}

*Corresponding author: Mohamed Nabih EL Gharib, Professor of Obstetrics \& Gynecology, Tanta University, Egypt.

To Cite This Article: Mohamed Nabih EL Gharib. Gestational Sleep Apnea. Am J Biomed Sci \& Res. 2019 - 2(5). AJBSR.MS.ID.000601. DOI: 10.34297/AJBSR.2019.02.000601

Received: March 19, 2019 | Published: April 25, 2019

\section{Introduction}

Sleep apnea is a concerning condition that can be life jeopardizing and is more common than commonly perceived. An empirical description of sleep apnea was first proposed in 1965 describing the condition as a disorder in breathing pattern that is distinctive by breathing anomalies occurring in the form of short abrupt interruptions in a patient's breathing pattern throughout their sleep. The word 'apnea' has a Greek etymological origin that is a derivative of the Greek word 'apnous' meaning 'breathless'. Obstructive sleep apnea is considered the most common type of sleep apnea taking place when air is impeded from flowing properly through the patient's nasal or oral cavities despite continuous attempts at breathing [1,2]. First time diagnosis of OSA in pregnancy is indicative of a condition named gestational obstructive sleep apnea. Empirical evidence has it that gestational OSA could improve or clear away altogether after delivery [3]. Two percent of middle-aged women are affected by obstructive sleep apnea (OSA). Moreover, the condition affects around $15-20 \%$ of obese pregnant women BMI > 40 kg.m-2. Pertinently, half of all pregnant women in the United States are either overweight or obese [4]. Pien along with colleagues found that at the two time points during pregnancy, a group of women who had undergone overnight polysomnography scored an increase from $10.5 \%$ in women with OSA in the first trimester to $26.7 \%$ in the third trimester.

\section{Causes}

The underlying factor behind obstruction in OSA was observed to be the collapse of the retrolingual and pharyngeal airway. The relaxation and sagging of the soft palate located at the base of the uvula and the tongue lead to a blockage in the airway which, in turn, causes breathing to become laborious and soundly and can even impede it exceedingly that it eventually stops entirely. Proper airway patency is considered to be maintained most primarily by the genioglossus muscle [4]. Estrogen depletion occurring during menopause poses as a potential risk factor for sleep breathing anomalies. Data extracted from a survey show that changes in the body mass index (BMI) are rarely accompanied by changes in (Apnoea-Hypopnoea Index). Besides, AHI and obesity are rather rarely associated in the elderly [5]. Women diagnosed with PCOS were more likely to develop OSA later in life [6]. Studies done previously have suggested a correlative relationship between PCOS and obesity as well as obesity and OSA. Nonetheless, empirical evidence has it that PCOS has an independent role to play in the development of OSA [7]. Interrelation between PCOS and OSA may be explained by the deregulation of the gonadal hormone related to PCOS [8].

\section{Clinical Picture}

Patients diagnosed with sleep apnea usually experience soundly snoring in their sleep (around 3 times a week or more on a weekly basis). Besides, they apparently struggle to breathe. Sleep apnea patients usually get noticed by colleagues or friends involuntarily falling asleep at inappropriate times during the day; like when they are driving a vehicle, working or conversing with others.

\section{Diagnosis}

One of the primary reasons OSA patients seek medical help is because their partners or roommates cannot sleep properly because of their soundly snoring. It is necessary for patients to get physically examined thoroughly, and it is of significant importance for their history to be checked [9]. Sleep health centers are often the places where patients undergo diagnostic tests; however, some kinds of sleep studies can be efficiently carried out at patients' houses by dint of modern advanced technology. Another common characteristic of sleep apnea is experiencing sensations of choking. Among the negative health consequences of sleep apnea are morning headaches along with strong proclivity toward sleepiness during daytime [10]. Nevertheless, empirical laboratory polysomnography (PSG) that is performed throughout the night while professionally attended is the most fundamental diagnostic standard for OSA [11].

\section{Complications}

Sleep apnea health consequences range from noisy and disturbing to life jeopardizing. Some of those consequences are made manifest in a patient's life in the form of irritability, sexual impotence, learning incapability, memory problems, depression and involuntarily falling asleep while working, driving or conversing. Up to 50 percent of sleep apnea patients have were 
estimated to have high blood pressure. Sleep apnea appears to have significant contribution to high blood pressure although it is not evident that there is a cause-and-effect correlation between the two conditions. Patients suffering from sleep apnea are at high risk for experiencing heart attacks and strokes. Moreover, sudden infant death syndrome has been observed to have sleep apnea implication [12]. A risk of exceeding significance poses for OSA female patients to enter pregnancy with chronic hypertension and/ or hypersensitive disorders of pregnancy (HDP). Such disorders include preeclampsia, eclampsia, gestational hypertension and chronic hypertension (Table 1). Outcome of maternal and neonatal in obstructive sleep apnea [13].

\begin{tabular}{|c|c|c|c|}
\hline & No OSA & OSA & $\mathrm{p}$-value \\
\hline $\begin{array}{l}\text { Uncomplicated } \\
\text { Pregnancy }\end{array}$ & $27(44.3 \%)$ & $5(26.3 \%)$ & 0.19 \\
\hline Gestational Diabetes & $9(14.8 \%)$ & $1(5.3 \%)$ & 0.4374 \\
\hline Cesarean Delivery & $36(59.0 \%)$ & $14(73.7 \%)$ & 0.2488 \\
\hline Estimated Blood Loss & $750[350,850]$ & $750[400,800]$ & 0.5576 \\
\hline Spontaneous Labor & $11(18.0 \%)$ & $3(15.8 \%)$ & 0.8222 \\
\hline Induction of Labor & $26(42.6 \%)$ & $6(31.6 \%)$ & 0.3909 \\
\hline $\begin{array}{l}\text { Oxytonic during } \\
\text { labor }\end{array}$ & $26(42.6 \%)$ & $5(26.3 \%)$ & 0.2026 \\
\hline $\begin{array}{c}\text { Adverse } \\
\text { cardiovascular } \\
\text { Outcome }\end{array}$ & $13(21.3 \%)$ & $8(42.1 \%)$ & 0.072 \\
\hline
\end{tabular}

NO OSA: Patients without obstructive sleep apnea

OSA: Patients with Obstructive sleep apnea

\section{Management}

Sleeping pills, tobacco and alcohol should be entirely avoided sleep apnea by patients as their usage paves the way for the airway to collapse and makes it likelier for the apneic episodes to become prolonged. It also is noteworthy that overweight patients can benefit significantly from weight loss. Pertinently, the number of apneic episodes experienced by overweight patients can be reduced right on losing as little as 10 percent of their body weight.

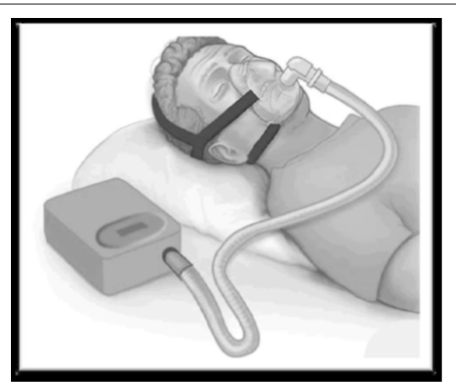

Figure 1: A patient using CPAP.

The most effective treatment for sleep apnea is commonly perceived to be nasal continuous positive airway pressure (CPAP).
The patient uses such a procedure by placing a mask right over the nose throughout their sleep, and air gets forced through the nasal passages by dint of the pressure caused by an air blower. The main function of the properly adjusted, constant and ongoing air pressure is to prevent throat collapsing during sleep. Airway blockage is prevented by dint of using nasal CPAP; however, sleep apnea episodes return on occasions when usage of CPAP is improper or stopped altogether (Figure 1). CPAP being used by a patient Women diagnosed with gestational sleep apnea during the course of their pregnancy are potentially at risk for a continuation of suffering from respiratory suppression of significant severity after delivery. Thus, usage of respiration suppressing medications should be professionally regulated and limited to a minimum.

\section{References}

1. Pien GW, Pack AI, Jackson N, Maislin G, Macones GA, et al. (2014) Risk factors for sleep-disordered breathing in pregnancy. Thorax 69 (4): 371377.

2. Jordan AS, McSharry DG, Malhotra A (2014) Adult obstructive sleep apnoea. Lancet 383(9918): 736-747.

3. Facco FL, Parker CB, Reddy UM, et al. (2015) NuMoM2b sleep-disordered breathing study: objectives and methods. Am J Obstet Gynecol 212(4): 542.e1-127.

4. Klawe JJ, Tafil Klawe M (2003) Age-related response of the genioglossus muscle EMG activity to hypoxia in humans. J Physiol Pharmacol 54(Suppl 1): $14-19$.

5. Young T, Finn L, Austin D, Peterson A (2003) Menopausal status and sleep-disordered breathing in the Wisconsin Sleep Cohort Study. Am J Respir Crit Care Med 2003;167(9): 1181-1185.

6. Lin TY, Lin PY, Su TP, Li CT, Lin WC, et al. (2017) Risk of developing obstructive sleep apnea among women with polycystic ovarian syndrome: a nationwide longitudinal follow-up study. Sleep Medicine 36: 165-169.

7. Dunaif A (2012) Polycystic ovary syndrome in 2011: genes, aging and sleep apnea in polycystic ovary syndrome. Nat Rev Endocrinol 8(2): 7274.

8. Li X, Feng Y, Lin JF, et al. (2014) Endometrial progesterone resistance and PCOS. J Biomed Sci 21(1): 2

9. Kingshott RN, Sime PJ, Engleman HM, Douglas NJ (1995) Self assessment of daytime sleepiness: patient versus partner. Thorax 50(9): 994-995.

10. Lockhart EM, Ben Abdallah A, Tuuli MG, Leighton BL (2015) Obstructive Sleep Apnea in Pregnancy: Assessment of Current Screening Tools. Obstet Gynecol 126(1): 93-102.

11. Kapur VK, Auckley DH, Chowdhuri S, et al. (2017) Clinical practice guideline for diagnostic testing for adult obstructive sleep apnea: an American Academy of Sleep Medicine Clinical Practice Guideline. J Clin Sleep Med 13(3): 479-504.

12. Louis JM, Mogos MF, Salemi JL, Redline S, Salihu HM (2014) Obstructive sleep apnea and severe maternal-infant morbidity/mortality in the United States, 1998-2009. Sleep 37(5): 843-849.

13. Dominguez JE, Grotegut CA, Cooter M, Krystal AD, Habib AS (2018) Screening extremely obese pregnant women for obstructive sleep apnea, American Journal of Obstetrics and Gynecology. Am J Obstet Gynecol 219(6): 613. 